\title{
Genetic Interactions of Pillar (Columnar), Compact, and Dwarf Peach Tree Genotypes
}

\author{
Ralph Scorza \\ U.S. Department of Agriculture, Agricultural Research Service, Appalachian Fruit Research Station, 45 \\ Wiltshire Road, Kearneysville, WV 25430 \\ Daniele Bassi \\ Department of Produzione Vegetale, University of Milan, Via Celoria, 2-20133 Milano, Italy \\ Alessandro Liverani \\ Istituto Sperimentale per la Frutticoltura, Sezione di Forli, Via Punta di Ferro, 2-47100 Forli, Italy
}

AdDitional INDEX WORDs. Prunus persica, growth habit, weeping, peach breeding

\begin{abstract}
A study was conducted to determine genetic control of the columnar or pillar (PI) growth habit, and to evaluate the effects of interactions of various genes that influence peach [Prunus persica (L.) Batsch (Peach Group)] growth habit. The PI habit (brbr) examined in this study was inherited as a monogenic trait expressing incomplete dominance. The heterozygous Brbr derived from crosses between standard (ST) and PI genotypes was recognized as an upright (UP) tree with narrower branch angles than ST trees but wider than PI trees. The combination of $b r b r$ and brachytic dwarf (DW) $(d w d w)$ produced dwarf-pillar (DWPI) trees. The effects of the heterozygous Brbr in combination with $d w$ and/or compact (CT) $(C t)$ could not be recognized by visual observation. Compact pillar (CTPI) trees resulted from the expression of $C t_{-}$ brbr. These trees were distinguished from globe-shaped (GL) trees $(\mathrm{Ct}$ _ Brbr) by the more upright growth habit of the CTPI trees. This genetic study highlights the genetic plasticity of tree growth habit in peach. The investigation of novel growth habits extends our concept of the peach tree. Some growth habits such as PI may have commercial potential for high-density peach production systems. Others, such as DWPI and CTPI may have potential as ornamentals.
\end{abstract}

Genetic manipulation of growth habit to control peach [Prunus persica (Peach Group)] tree size and shape offers an alternative to pruning (Emerson and Hayden, 1975; Hayden and Emerson, 1979; Horton, 1985; Marini and Sowers, 2000), root restriction (Glenn and Miller, 1995), irrigation control (Chalmers et al., 1981; Glenn, 2000), and other vigor-controlling methods. A number of different peach tree growth habits have been identified and their inheritance determined. These include brachytic dwarf (DW) $(d w d w)$ (Hooper, 1867; Strong, 1867), semidwarf (SD) (Fideghelli et al., 1979), pillar (PI) (brbr) (Yamazaki et al., 1987), compact (CT) (Ct_) (Van Well, 1974), weeping (WE) (plpl) (Monet et al., 1988; Yamazaki et al., 1987), and spur-type (SP) (Scorza, 1987). Development of new peach cultivars with DW, $\mathrm{SD}$, and PI growth habit is being actively pursued by several peach breeding programs world-wide (Bassiet al., 1994; Fideghelli et al., 1979; Scorza et al., 2000).

While inheritance of alternate peach tree growth habits has been reported (Conners, 1920; Mehlenbacher and Scorza, 1986; Yamazaki et al., 1987), along with information concerning their growth and pruning requirements (Bassi and Rizzo, 2000; Bassi et al., 1994; Scorza, 1984; Scorza et al., 1984, 1986), there is little information concerning the interaction of genes affecting growth habit following hybridization (Yamazaki et al., 1987). Such information would be useful in development of new growth types for commercial peach production or for ornamental use. Therefore, the objective of the present study was to determine genetic control of the columnar or PI growth habit, and to evaluate the effects of interactions of $C t, b r, p l$, and $d w$ genes on peach tree growth habit.

Received for publication 5 Apr. 2001. Accepted for publication 11 Nov. 2001. The authors extend appreciation to M. Demuth and L. Gilreath for excellent technical assistance in tree production and evaluation of growth habit and M. Pooler for assistance in data analysis.

\section{Materials and Methods}

Parental Germplasm. The CT genotype ('Com-Pact Redhaven') was discovered in 1964 as a bud mutation of 'Redhaven'(Van Well, 1974). 'Com-Pact Redhaven' was crossed with 'Empress Dwarf' (Brooks and Olmo, 1971) and produced a number of seedlings, one of which, KV77119, a CT tree, was heterozygous for the compact gene $(C t c t)$ and the brachytic dwarf gene $(D w d w)$. KV77119 was crossed with a showy-flowered pillar (SFP) tree (see below). Progeny segregated in a ratio of 1 globe-shaped (GL) : 1 upright (UP) (Scorza et al., 1989). A pedigree and proposed phenotypes and genotypes of parental, $\mathrm{F}_{1}$, $\mathrm{F}_{2}$ and $\mathrm{F}_{3}$ trees used in this study are presented in Fig. 1.

TEST FOR ALLELISM IN PI sourCES. Two sources of PI were used in this study. Both were obtained from L. F. Hough [Rutgers University, New Brunswick, N.J. (deceased)]. They were imported originally from Japan. The growth form of these two PI clones was similar. One genotype, SFP, produced double showy variegated flowers and small, bitter, melting, white-flesh fruit. SFP appears to be similar, if not identical, to the Japanese cultivar, Hoki (Yamazaki et al., 1987). The second genotype, a nonshowy-flowered pillar (NSP), produced nonshowy flowers and yellow, non-melting flesh fruit. Differences in fruit and flower phenotypes and the absence of information concerning their precise origins led to questions concerning the allelic identity of these two PI genotypes. In order to test for allelism between the PI genes in SFP and NSP, heterozygous redleaf SFP, developed at the Appalachian Fruit Research Station, Kearneysville, W.Va., was used as a pollen parent to hybridize with NSP. While green-leaf pillar progeny from this cross could have resulted from self-pollination of the female green-leaf NSP parent, red-leaf trees could only result from hybridization between the redleaf SFP and the green leaf NSP since there were no other red-leaf trees in the block or adjacent blocks. Hybrids were also produced between a tree heterozygous for both PI (from SFP) and red-leaf, and a green-leaf NSP. If the PI genes were allelic, a 1 PI : 1 UP ratio 
would be expected along with 1 red-leaf : 1 green-leaf. Red-leaf PI trees would be most diagnostic because these could only result from cross-hybridization as opposed to self-pollination of the greenleaf parent that could have occurred unintentionally.

HYBRIDIZATION OF PI WITH ST, DW, AND WE PHENOTYPES. SFP and NSP were hybridized with standard (ST) growth habit peach cultivars, and DW and WE peach phenotypes. The PI parent was used as a male or female parent depending on the cross, but reciprocal crosses using the

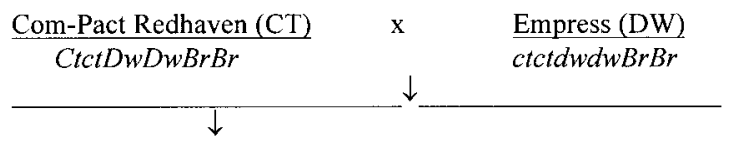

\section{Parental}

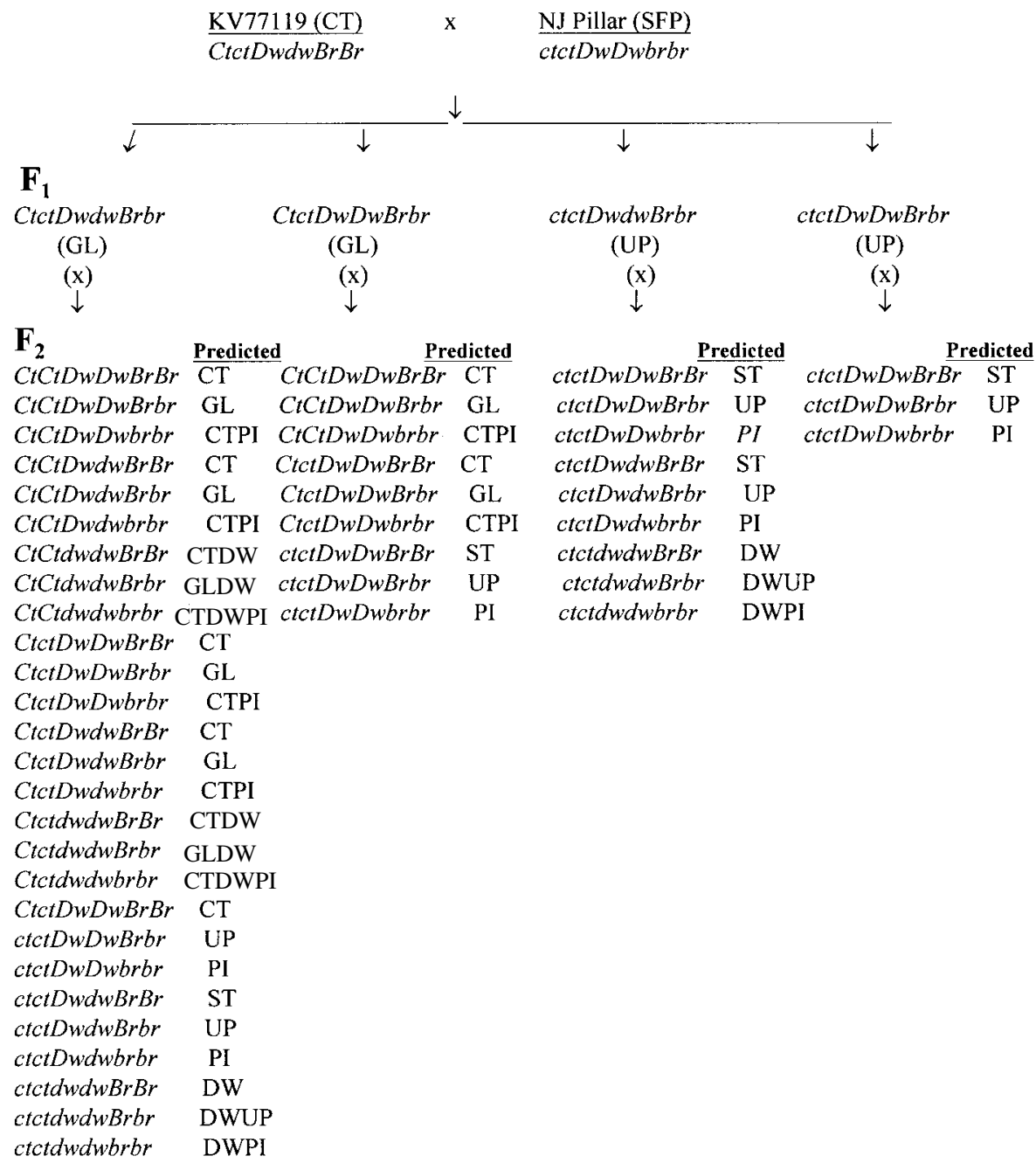

\section{$\mathbf{F}_{3}$}

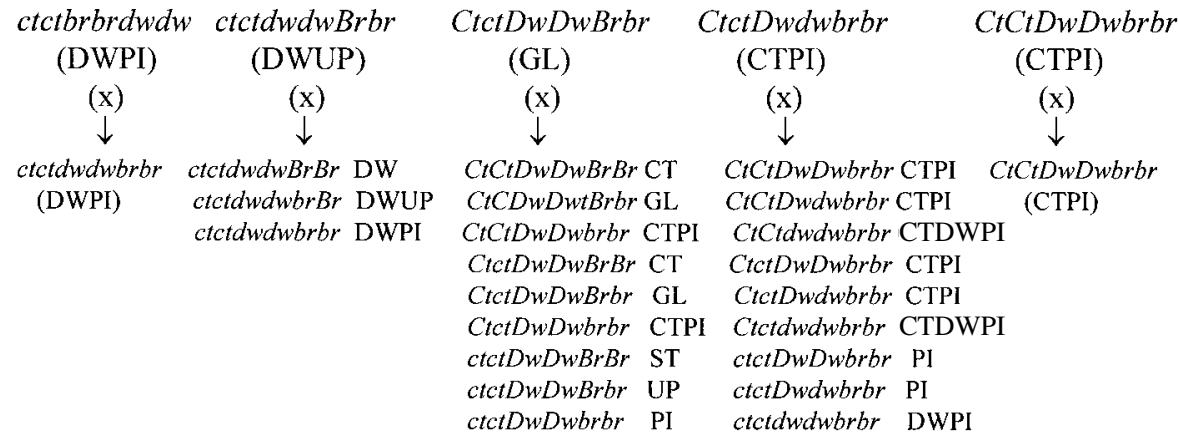

same parents were not performed. The general hybridization method was as described in Scorza and Sherman (1996). Self-pollination was achieved by covering trees with parachutes from pre-bloom until petal fall (Werner and Cain, 1985). Fruit were harvested, seeds were removed from the endocarps and stratified (moist pre-chilled) at $5^{\circ} \mathrm{C}$ for 2 months or until radicals appeared, planted in a medium of 3 peat: 1 perlite (by volume), and fertilized monthly with a water soluble fertilizer containing $10 \mathrm{~N}-4 \mathrm{P}-8 \mathrm{~K}$. Seedlings were field planted, left unpruned, and evaluated forgrowth habitafter 1 to 4 years in the field. Trees were fertilized with $325 \mathrm{~kg} \cdot \mathrm{ha}-{ }^{1}$ of $10 \mathrm{~N}-4 \mathrm{P}-8 \mathrm{~K}$ in the spring of each year. Herbicides, insecticides, and fungicides were applied as needed during the growing seasons.

DEVELOPMENT OF $\mathbf{F}_{2}$ AND $\mathbf{F}_{3}$ POPUlations. Five $F_{1}$ GL and 10 UP trees from the cross KV77119 x SFP were self-pollinated by covering trees with parachutes. Following stratification and germination, seedlings grew for 9 months in a greenhouse and were planted in the field in September 1987 at a spacing of $2 \mathrm{~m}$ within rows and $6 \mathrm{~m}$ between rows. Growth habit was evaluated independently by two observers following two seasons of growth and again during the fourth season of growth in the field. Based on field observations, nondwarf trees were placed into one of six phenotypic classes: ST, UP, PI, CT, GL, or Compact Pillar (CTPI). DW trees were rated as DW or pillar dwarf (DWPI). The difference in growth between some of these tree types was subtle. Examples of some of these tree types were self-pollinated to produce $\mathrm{F}_{3}$ populations to further clarify the combination of genes in particular trees expressing subtle differences in growth habit. The phenotypes selected included GL, CTPI, DW, and DWPI. Seeds were germinated and seedlings grown in a manner similar to that of the $\mathrm{F}_{2}$ trees and evaluated after $1,2,3$, and 5 years in the field.

\section{Results}

Test for allelism of $P$ i Gene. Two populations of hybrid progeny (64 trees, and 11 trees) resulted from crosses of green-leaf NSP $x$ red-leaf SFP. All progeny, whether green- or red-leaf, were PI (Table 1). Cross 1 produced an excess of green-leaf progeny indicating that some of the progeny were products of self-pollination of the green-leaf NSP. Both crosses of green-leaf NSP by red-leaf UP produced phenotypic ratios of 1 PI : 1 UP. These crosses also produced

Fig. 1. Pedigree of peach tree parents and segregating progeny evaluated for expression of growth habit (phenotypes and proposed genotypes); $\mathrm{x}=$ self pollination and predicted indicates predicted phenotypes with $\mathrm{CT}=$ compact, $\mathrm{GL}=$ globe-shaped, $\mathrm{PI}=$ pillar, DW = dwarf, CTPI = compact pillar, $\mathrm{DWUP}=$ upright dwarf, DWPI $=$ pillar dwarf, $\mathrm{ST}=$ standard, UP = upright, DWCTPI=dwarf compact pillar, $\mathrm{DWCT}=$ dwarf compact, $\mathrm{DWGL}=$ dwarf globeshaped. 
more green-leaf PI than expected again indicating some selfpollination. Over all crosses, these results indicated that the PI growth habit from SFP and NSP resulted from the expression of the same gene.
InHeritance OF Pi. Self-pollinated PI trees produced only PI (Table 2). PI crossed with ST produced primarily one tree type (UP) characterized by a more upright growth than ST trees (Fig. 2). This upright growth was more clearly evident in some crosses than in

Table 1. Tests of allelism of the pillar gene from SFP and NSP sources using green-leaf ( $\mathrm{grgr}$ ) parents $\mathrm{x}$ heterozygous red-leaf $(\mathrm{Grgr})$ parents.

\begin{tabular}{|c|c|c|c|c|c|c|c|c|}
\hline \multirow[b]{3}{*}{$\operatorname{Cross}^{\mathrm{z}}$} & \multirow[b]{2}{*}{ Pillar } & \multirow[b]{2}{*}{ Nonpillar } & & & \multicolumn{4}{|c|}{ Leaf color } \\
\hline & & & & & Red & Green & & \\
\hline & \multicolumn{2}{|c|}{ (no. trees) } & $\chi^{2}$ & $P$ & \multicolumn{2}{|c|}{ (no. trees) } & $\chi^{2}$ & $P$ \\
\hline$\overline{\mathrm{GR} N S P} \times \mathrm{RL} \mathrm{SFP}^{\mathrm{y}, \mathrm{x}}$ & 64 & 0 & 0 & 0.99 & 25 & 39 & 3.06 & $0.05-0.1$ \\
\hline GR NSP $x$ RL SFP ${ }^{y, x}$ & 11 & 0 & 0 & 0.99 & 6 & 5 & 0.09 & $0.70-0.80$ \\
\hline GR NSP $x$ RL SFUP ${ }^{w x}$ & 51 & 41 & 1.09 & $0.2-0.3$ & 36 & 56 & 4.35 & $0.02-0.05$ \\
\hline GR NSP $x$ RL SFUP ${ }^{w x}$ & 57 & 59 & 0.03 & $0.8-0.9$ & 50 & 66 & 2.21 & $0.10-0.20$ \\
\hline
\end{tabular}

${ }^{\mathrm{z}} \mathrm{GR}$ = green-leaf; RL = red-leaf, NSP = nonshowy-flowered pillar, SFP = showy-flowered pillar, and SFUP = showy-flowered upright.

${ }^{\mathrm{y}} \chi^{2}$ ratio tested for growth habit $=$ all PI.

${ }^{\mathrm{x}} \chi^{2}$ ratio tested for leaf color $=1$ Red : 1 Green.

${ }^{\mathrm{w}} \chi^{2}$ ratio tested for growth habit $=1$ PI $: 1$ non-PI.

Table 2. Segregation of peach tree growth type.

\begin{tabular}{|c|c|c|c|c|c|c|c|}
\hline \multirow[b]{2}{*}{$\operatorname{Cross}^{\mathrm{z}}$} & & \multicolumn{3}{|c|}{$\begin{array}{l}\text { Progeny } \\
\text { (no. trees) }\end{array}$} & \multirow{2}{*}{$\begin{array}{c}\text { Expected } \\
\text { ratio }\end{array}$} & \multirow[b]{2}{*}{$\chi^{2}$} & \multirow[b]{2}{*}{$P$} \\
\hline & & ST & UP & PI & & & \\
\hline \multirow[t]{10}{*}{$\overline{\mathrm{ST}} \times \mathrm{PI}$} & Pegaso $\times$ NSP & 4 & 105 & 0 & & & \\
\hline & Suncrest $\times$ NSP & 17 & 103 & 0 & & & \\
\hline & Supergem $\times$ NSP & 2 & 35 & 0 & & & \\
\hline & Cesarini x NSP & 0 & 8 & 0 & & & \\
\hline & IFF100 x NSP & 0 & 31 & 0 & & & \\
\hline & IFF101 x NSP & 1 & 37 & 0 & & & \\
\hline & City32-82 x NSP & 0 & 9 & 0 & & & \\
\hline & Firered $x$ NSP & 0 & 28 & 0 & & & \\
\hline & Maria Aurelia x NSP & 0 & 7 & 0 & & & \\
\hline & Total & 24 & 363 & 0 & $0: 1: 0$ & 1.43 & $0.20-0.30$ \\
\hline $\mathrm{PI} \times \mathrm{ST}$ & NSP $\times$ Springbelle & 0 & 67 & 3 & $0: 1: 0$ & 0.089 & $0.30-0.50$ \\
\hline \multirow[t]{4}{*}{$\mathrm{UP} \times \mathrm{ST}$} & (Suncrest $\times$ NSP) $\times$ StarMay & 2 & 10 & & & & \\
\hline & (Pegaso $\times$ NSP) $\times$ StarMay & 30 & 29 & 5 & & & \\
\hline & (NSP $\times$ Springbelle) $\times$ Royal Glory & 8 & 4 & 4 & & & \\
\hline & Total & 40 & 43 & 9 & $1: 1: 0$ & 0.979 & $0.50-0.70$ \\
\hline ST $\times$ UP & Springlady $\times($ NSP $\times$ Springbelle $)$ & 9 & 11 & 0 & $1: 1: 0$ & 0.005 & $0.90-0.95$ \\
\hline \multirow[t]{6}{*}{ UP $\times$ UP } & (Suncrest $\times$ NSP $) \times($ Pegaso $\times$ NSP $)$ & 8 & 17 & 7 & & & \\
\hline & {$[($ Suncrest $\times$ K2 $) \times \mathrm{NSP}] \times($ SFP $\times$ Redskin $)$} & 11 & 18 & 9 & & & \\
\hline & (Pegaso $\times$ NSP) selfed & 28 & 54 & 30 & & & \\
\hline & (Pegaso $\times$ NSP) selfed & 8 & 13 & 9 & & & \\
\hline & (Suncrest $\times$ NSP) selfed & 5 & 13 & 6 & & & \\
\hline & Total & 60 & 115 & 61 & $1: 2: 1$ & 0.161 & $0.90-0.95$ \\
\hline \multirow[t]{2}{*}{$\mathrm{UP} \times \mathrm{PI}$} & {$[(\text { Bounty } \times \text { NSP }) \times(\text { Fire Red } \times \text { NSP })(U P)]^{y}$} & & & & & & \\
\hline & [Flavortop $\times$ NSP $) \times($ Fire Red $\times$ NSP $)(\mathrm{PI})]$ & 0 & 29 & 38 & $0: 1: 1$ & 2.1 & $0.10-0.20$ \\
\hline \multirow[t]{4}{*}{ PI self-pollinated ${ }^{\mathrm{x}}$} & SFP & 0 & 0 & 13 & & & \\
\hline & NSP & 0 & 0 & 19 & & & \\
\hline & NSP & 0 & 0 & $22^{\mathrm{x}}$ & & & \\
\hline & Total & 0 & 0 & 54 & $0: 0: 1$ & 0 & 0.99 \\
\hline $\mathrm{WE} \times \mathrm{PI}^{\mathrm{x}}$ & $91459 \times \mathrm{NSP}$ & 0 & 47 & 0 & $0: 1: 0$ & 0 & 0.99 \\
\hline \multirow[t]{5}{*}{$\mathrm{DW} \times \mathrm{PI}^{\mathrm{x}}$} & Empress (op op) $x$ SFP ${ }^{x}$ & 0 & 18 & 0 & & & \\
\hline & Empress (op op) x SFP & 0 & 19 & 0 & & & \\
\hline & Empress (op op) x SFP & 0 & 21 & 0 & & & \\
\hline & Valley Red x NSP & 0 & 31 & 0 & & & \\
\hline & Total & 0 & 89 & 0 & $0: 1: 0$ & 0.025 & $0.80-0.90$ \\
\hline $\mathrm{PI} \times \mathrm{CT}$ & NSP $\times$ Elbertita & 0 & 14 & 0 & $0: 1: 0$ & 0.141 & $0.70-0.80$ \\
\hline
\end{tabular}

${ }_{\mathrm{z}}^{\mathrm{ST}}=$ standard growth form, UP = upright; PI = pillar, NSP = nonshowy flowered pillar, WE = weeping, DW = dwarf, op op = second generation derived from open pollinations, and SFP = showy-flowered pillar.

yProgeny from an open-pollinated tree.

${ }^{\mathrm{x}}$ Original parental NSP and SFP trees. 
Table 3. Summary of segregation of the pillar (PI) phenotype in progeny of self-pollinated UP $(\mathrm{Brbr})$ trees.

\begin{tabular}{|c|c|c|c|c|}
\hline \multirow{2}{*}{$\begin{array}{l}\text { Parent }^{\mathrm{Z}} \\
\text { no. }\end{array}$} & \multicolumn{2}{|c|}{ Progeny (no. trees) } & \multirow[b]{2}{*}{$\chi^{2}$} & \multirow[b]{2}{*}{$\mathrm{P}$} \\
\hline & Nonpillar & pillar & & \\
\hline$\overline{64}$ & 174 & 35 & 7.11 & $<0.01$ \\
\hline 66 & 266 & 104 & 1.91 & $0.10-0.20$ \\
\hline 72 & 93 & 37 & 0.83 & $0.30-0.50$ \\
\hline 76 & 154 & 76 & 7.93 & $<0.01$ \\
\hline 79 & 42 & 16 & 0.21 & $0.10-0.20$ \\
\hline 81 & 173 & 60 & 0.07 & $0.70-0.80$ \\
\hline 83 & 81 & 24 & 0.26 & $0.10-0.20$ \\
\hline 84 & 132 & 37 & 0.87 & $0.30-0.50$ \\
\hline 91 & 56 & 20 & 0.07 & $0.70-0.80$ \\
\hline 94 & 16 & 3 & 0.86 & $0.30-0.50$ \\
\hline \multicolumn{5}{|c|}{$\begin{array}{l}\text { Expected ratio } 3 \text { nonpillar : } 1 \text { pillar } \\
\chi^{2}\end{array}$} \\
\hline Pooled & & & 0.46 & $0.30-0.50$ \\
\hline Sum & & & 20.12 & $0.02-0.05$ \\
\hline Hetero & & & 19.66 & 0.02 \\
\hline
\end{tabular}

${ }^{\mathrm{z}}$ Parent trees were upright tree form (UP) $\mathrm{F}_{1}$ progeny of the cross KV77119, a compact (CT) growth habit tree, and a showy-flowered pillar (SFP) tree.

others. Self-pollinated UP trees together with UP x UP crosses produced the expected $1 \mathrm{ST}: 2 \mathrm{UP}: 1$ PI ratio. UP trees backcrossed with PI trees produced 1 : 1 UP to PI trees (Table 2). These data indicate that the PI growth habit is controlled by a single incompletely dominant gene. When PI was crossed with DW or WE, UP trees were produced (Table 2).

InTERACTION OF PI, DW, CT-F 2 GENERATION. Pillar. Segregation data from progeny of self-pollinated $\mathrm{F}_{1} \mathrm{UP}$ parents, supported previous data indicating that the PI phenotype is controlled by a
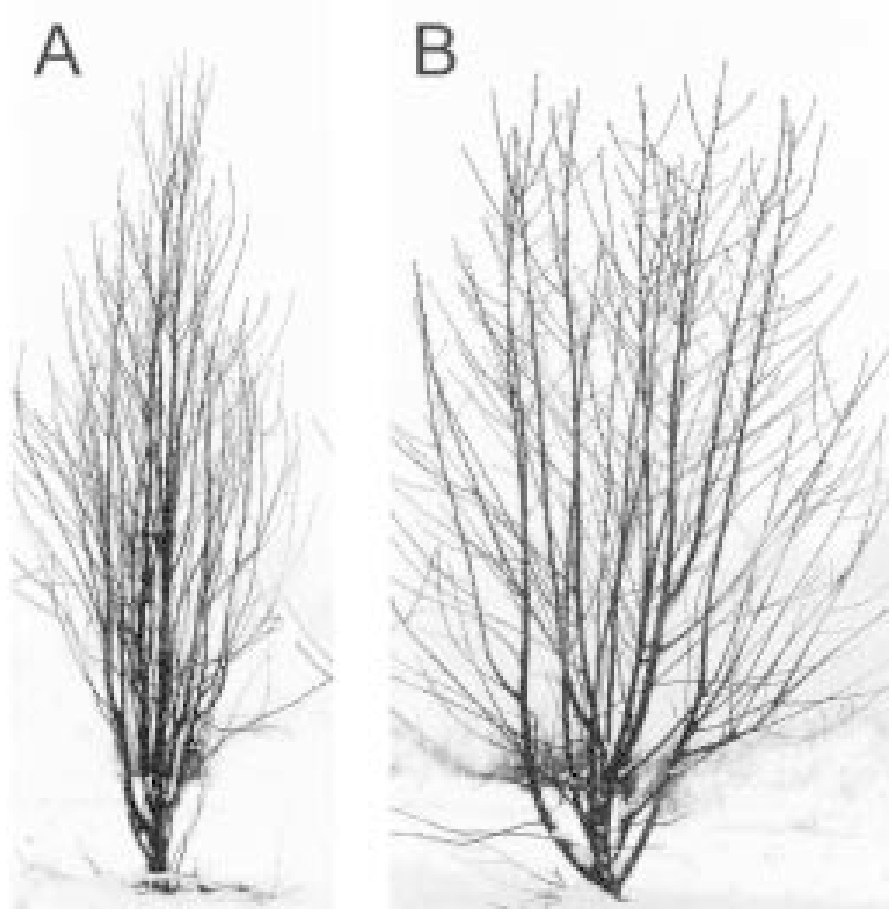

Fig. 2. (A) Nonpruned pillar (PI) seedling ( $b r b r)$ and (B) nonpruned upright (UP) $(B r b r)$, seedling 3 years in the field. Tree heights are $\approx 3 \mathrm{~m}$. single gene (Yamazaki et al., 1987). Over all crosses, progeny segregated into 3 nonpillar $(B r B r, B r b r)$ : 1 pillar $(b r b r)$, with acceptable chi-square values (Table 3 ). Independent evaluations by two observers resulted in consistent classification of trees as pillar or nonpillar. The difference between the $\mathrm{BrBr}$ genotype (ST tree phenotype) and the $B r b r$ genotype (UP tree phenotype) in these $\mathrm{F}_{2}$ populations was more dependent on the subjective interpretation of the observer, as evidenced by a large number of discrepancies in classification between standard $(\mathrm{Br} B r)$ vs. upright $(\mathrm{Br} b r$ ) (data not presented). Chi-square values on total trees observed using a 1 standard : 2 upright : 1 pillar model of no dominance were unacceptably large (pooled $\chi^{2}=90.59, P<0.001$; sum of $\chi^{2}=99.16, P<$ 0.001). This difficulty in discrimination between $\mathrm{BrBr}$ and $\mathrm{Brbr}$ in these populations may have been due to confounding effects of environment and interlocus interactions related to the genetic backgrounds of the original parental germplasm including 'Com-pact Redhaven' and 'Empress'.

Compact. Previous work has shown that the compact allele is inherited as a simple Mendelian dominant $(C t)$, producing a 3:1 segregation of compact to noncompact progeny (Mehlenbacher and Scorza, 1986). In the current study, expression of the $C t$ gene was evaluated by grouping all trees that expressed characteristics typical of compact growth, specifically dense branching habit, increased

Table 4. Segregation of compact (CT) and non-CT growth types [grouping CT and CT pillar (CTPI) as CT, and standard and pillar as non$\mathrm{CT}$ ] in progenies of four self-pollinated $\mathrm{CtctBrbr}$ trees. Chi-square values are based on the expected frequency of $3 \mathrm{CT}: 1$ non-CT (Mehlenbacher and Scorza, 1986).

\begin{tabular}{lcccc}
\hline \hline Self-pollinated & \multicolumn{2}{c}{ Progeny (no.) } & & \\
\cline { 2 - 3 } parent $^{\mathrm{z}}$ & Compact & Noncompact & & $\chi^{2}$ \\
\hline Tree 63 & 27 & 8 & 0.081 & $0.70-0.80$ \\
Tree 65 & 60 & 25 & 0.662 & $0.30-0.50$ \\
Tree 87 & 43 & 15 & 0 & 0.99 \\
Tree 89 & 104 & 49 & 4.19 & $0.02-0.05$ \\
$\chi^{2}$ & & & & \\
$\quad$ Pooled & & & 1.73 & $0.10-0.20$ \\
$\quad$ Sum & & & 4.93 & $0.20-0.30$ \\
$\quad$ Heterogeneity & & & 3.20 & $0.30-0.50$ \\
\hline
\end{tabular}

${ }^{\mathrm{z}}$ Parent trees were globe-shaped (GL) tree form, $\mathrm{F}_{1}$ progeny of the cross KV77119, a compact (CT) growth habit tree and a showy-flowered pillar (SFP) tree. For genotypes of progeny see Fig. 1.

Table 5. Phenotypes, expected genotypes, expected frequencies, and mean observed frequencies of six observed classes of progeny from self-pollinated CtctBrbr peach trees.

\begin{tabular}{lccc}
\hline \hline Phenotype & $\begin{array}{l}\text { Expected } \\
\text { genotype }\end{array}$ & $\begin{array}{c}\text { Expected } \\
\text { frequency }\end{array}$ & $\begin{array}{c}\text { Mean observed } \\
\text { frequency }^{z}\end{array}$ \\
\hline Compact & $C t C t B r B r$ & $1 / 16$ & \\
& $C t c t B r B r$ & $2 / 16$ & $25 \%$ \\
Globe & CtCtBrbr & $2 / 16(19 \%)$ & \\
& $C t c t B r b r$ & $4 / 16$ & $27 \%$ \\
Compact pillar & CtCtbrbr & $6 / 16(38 \%)$ & \\
& $C t c t b r b r$ & $1 / 16$ & $19 \%$ \\
Standard & & $2 / 16$ & $8 \%$ \\
Upright & $c t c t B r B r$ & $1 / 16(16 \%)$ & $12 \%$ \\
Pillar & $c t c t B r b r$ & $2 / 16(12 \%)$ & $9 \%$ \\
\hline
\end{tabular}

${ }^{\mathrm{z}}$ Mean phenotypic frequency in four $\mathrm{F}_{2}$ populations $(63,65,87,89)$. 
Table 6. Segregation of compact (CT), globe-shaped (GL), compact-pillar (CTPI), pillar (PI), upright (UP), and standard (ST) peach tree growth types in progenies of four self-pollinated CtctBrbr trees. Chi-square values are based on the expected frequencies listed in Table 5.

\begin{tabular}{|c|c|c|c|c|c|c|c|c|}
\hline \multirow{2}{*}{$\begin{array}{l}\text { Self-pollinated } \\
\text { parent }^{z}\end{array}$} & \multicolumn{6}{|c|}{ Progeny } & \multirow[b]{2}{*}{$\chi^{2}$} & \multirow[b]{2}{*}{$P$} \\
\hline & CT & GL & CTPI & PI & UP & $\overline{\mathrm{ST}}$ & & \\
\hline Tree 63 & 9 & 9 & 9 & 2 & 4 & 2 & 3.16 & $0.50-0.70$ \\
\hline Tree 65 & 15 & 29 & 16 & 6 & 11 & 8 & 1.67 & $0.80-0.90$ \\
\hline Tree 87 & 21 & 11 & 11 & 7 & 4 & 4 & 19.35 & $0.01-0.001$ \\
\hline Tree 89 & 38 & 40 & 26 & 13 & 22 & 14 & 12.25 & $0.02-0.05$ \\
\hline \multicolumn{9}{|l|}{$\chi^{2}$} \\
\hline Pooled & & & & & & & 5.93 & $0.30-0.50$ \\
\hline Sum & & & & & & & 36.43 & $0.01-0.02$ \\
\hline Heterogeneity & & & & & & & 30.50 & $0.01-0.02$ \\
\hline
\end{tabular}

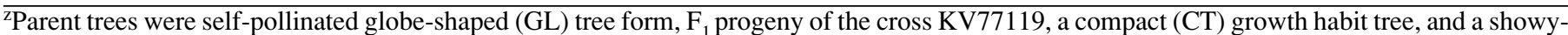
flowered pillar (SFP) tree.

branch angle, and reduced height (Mehlenbacher and Scorza, 1986; Scorza et al., 1989), as CT genotypes. These evaluations confirmed the expected 3:1 ratio (Table 4). In the $F_{2}$ populations that we studied, the $\mathrm{CT}$ phenotype $(\mathrm{Ct} \mathrm{BrBr})$ was not well distinguished from GL $(C t B r b r)$, a tree type characterized by a uniformly round, dense canopy, the former being over-represented and the latter under-represented.

Interaction of pillar and compact. Segregation of the PI $(b r)$ and CT $(C t)$ genes appeared to be independent, based on an insignificant contingency chi-square $(2.104, P=0.1-0.25)$. Expected dihybrid ratios of $C t$ and $b r$ are indicated in Table 5, and segregation data of the $C t$ and $b r$ genes from four self-pollinated $C t c t B r b r$ individuals are presented in Table 6.

Dwarf. The brachytic dwarf used in this study is controlled by a single recessive gene $(d w)$ (Lammerts, 1945). Tree KV77119 which is heterozygous for the dwarfing gene $(D w d w)$ was crossed with SFP, which contains no known dwarfing alleles. The progeny would have segregated in a $1 D w D w: 1 D w d w$ ratio. As expected, approximately half of the offspring trees evaluated were heterozygous for the dwarfing gene (nine out of 15 trees, chi square $=0.6, P=0.25$ $0.50)$, as indicated by the presence of dwarf trees in their progeny derived from self-pollination $\left(\mathrm{F}_{2}\right.$ generation). In the $\mathrm{F}_{2}$ generation there were fewer DW trees from each DW-producing parental combination than expected (pooled $\chi^{2}=35.75 P=<0.001$; sum of $\chi^{2}=56.95 P=0.001-0.01$ ), probably due to relatively high seedling mortality of the dwarf phenotype in the greenhouse due to shading from non-DW seedlings grown at close spacing.

Interaction of dwarf with compact and pillar. In the field, young DW trees, due to their small size, can be easily damaged by herbicides and cultivation equipment, and, in fact, $45 \%$ of DW trees died within a few years of planting in the field. Many of the surviving DW trees could be classified as DW or DWPI (Fig. 3). However, an interaction of DW with $\mathrm{Brbr}$ (UP) couldnotbedistinguishedanditisnotknownif $d w d w B r b r$ trees would be more likely classified as DWPI or DW. Further, the growth habit of trees combining $d w d w$ with $C t$, or $d w d w$ with $C t$ and brbris unclearand couldhave influenced the classification of growth habits. If it is assumed that any tree expressing $d w d w$ would, infact, be a DW tree there is the possibility that some of these combinations, particularly DW + CT could produce very small, compact-dwarf trees, more prone to seedling mortality. Specific studies of dwarf trees expressing combinations of growth habit genes may be necessary to assess the interactions of these genes with $d w d w$.

F $_{3}$ GENERATION. Selfed trees classified as GL. Prior work with GL trees (Scorza et al., 1989) suggested that this phenotype was a result of expression of both the PI and CT genes. In the $F_{1}$ hybrids described in that report, the GL trees would have been the result of combining PI in a heterozygous state with the CT heterozygote, the
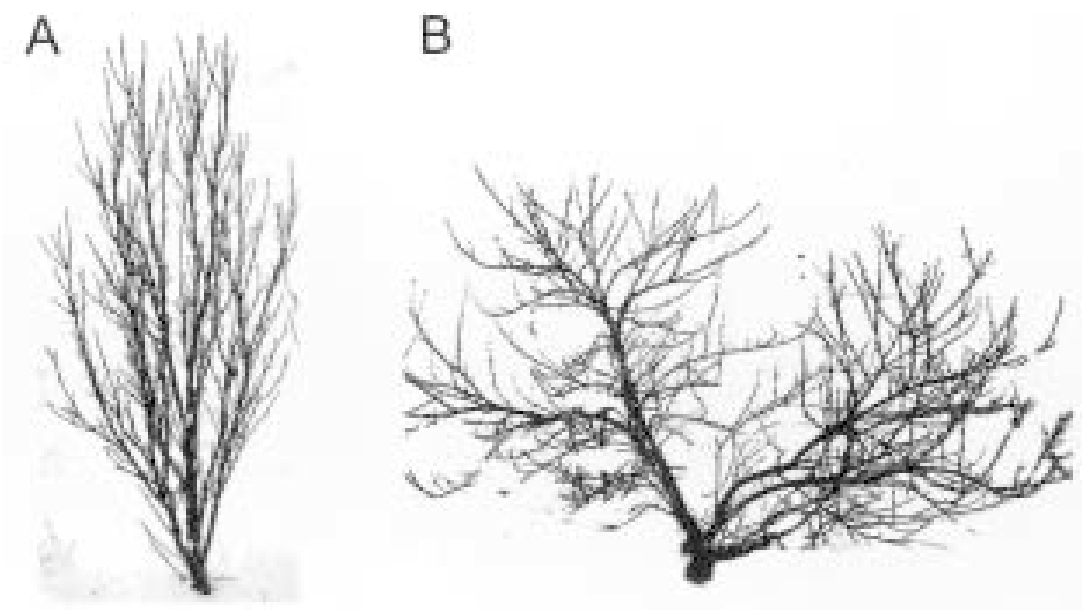

Fig. 3. Nonpruned pillar dwarf (DWPI) (left) and dwarf (DW) (right) peach, 10 years in the field. DWPI tree height is $2.2 \mathrm{~m}$.

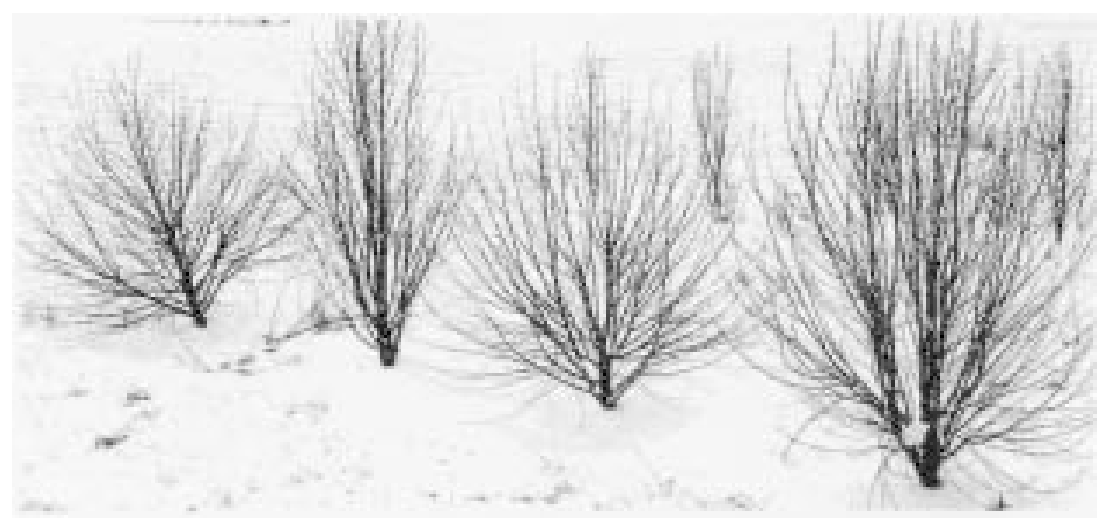

Fig. 4. (left to right) Nonpruned compact (CT) (1.7 $\mathrm{m}$ tall), pillar (PI) (2.1 m tall), globe-shaped (GL) (1.6 $\mathrm{m}$ tall), and compact pillar (CTPI) (1.8 m tall) peach sibling seedlings, 2 years in the field. 
Table 7. Segregation of peach tree growth habit in the $\mathrm{F}_{3}$ generation progeny of self-pollinated $\mathrm{F}_{2}$ trees with or without overall grouping (pooling) of Compact (CT) and non-CT trees.

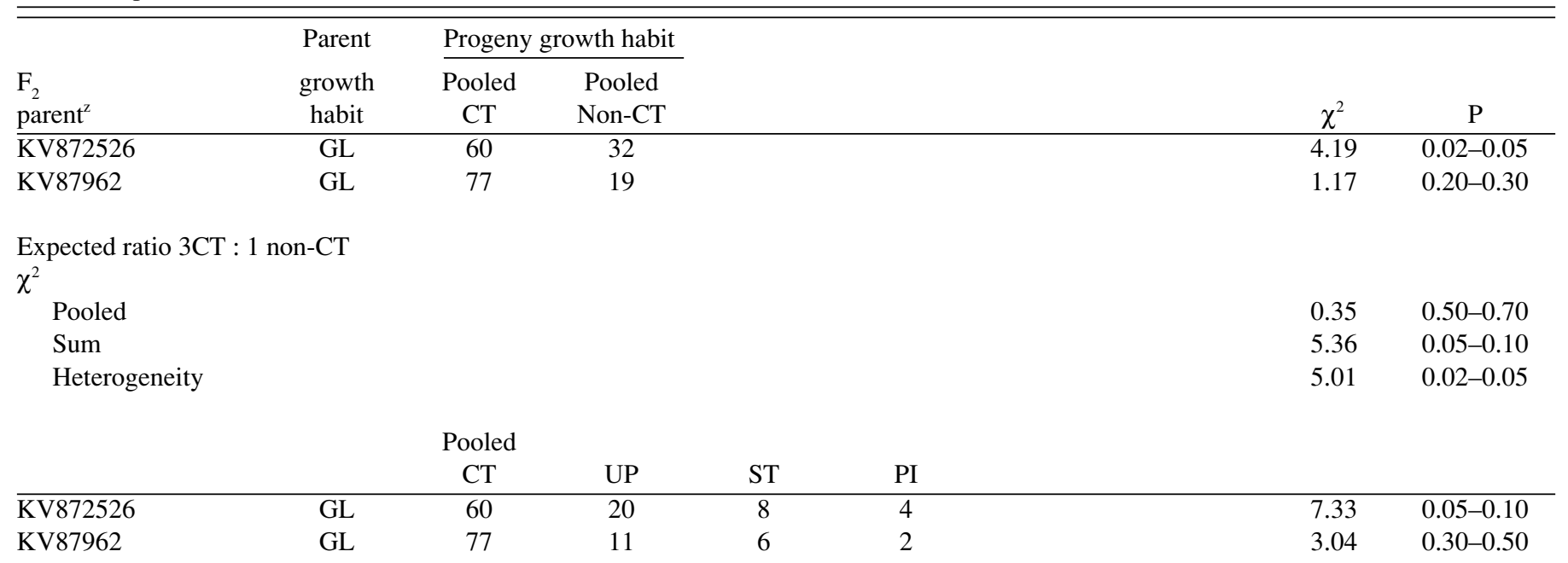

Expected ratio $12 \mathrm{CT}: 1 \mathrm{UP}: 2 \mathrm{ST}: 1 \mathrm{PI}$

$\chi^{2}$

$\begin{array}{lr}\text { Pooled } & 4.81 \\ \text { Sum } & 0.10-0.20 \\ \text { Heterogeneity } & 0.10-0.20 \\ & 5.56 \\ & 0.10-0.20\end{array}$

\begin{tabular}{|c|c|c|c|c|c|c|c|c|c|}
\hline & & CT & CTUP & CTPI & UP & ST & PI & & \\
\hline$\overline{K V 872526}$ & GL & 27 & 21 & 12 & 20 & 8 & 4 & 18.7 & $<0.001$ \\
\hline KV 87962 & GL & 39 & 15 & 23 & 11 & 6 & 2 & 39.6 & $<0.001$ \\
\hline
\end{tabular}

Expected ratio $3 \mathrm{CT}: 6 \mathrm{CTUP}: 3 \mathrm{CTPI}: 2 \mathrm{UP}: 1 \mathrm{ST}: 1 \mathrm{PI}$

$\chi^{2}$

$\begin{array}{lr}\text { Pooled } & 46.8 \\ \text { Sum } & 50.001 \\ \text { Heterogeneity } & <0.001 \\ & 0.20-0.30\end{array}$

${ }^{\mathrm{Z}} \mathrm{KV} 87962$ is an $\mathrm{F}_{2}$ progeny of self-pollinated globe-shaped (GL) $\mathrm{F}_{1}$ seedling tree 63 from the cross KV77119, a compact (CT) growth habit tree, and a showy-flowered pillar (SFP) tree. KV872526 is an $\mathrm{F}_{2}$ progeny of self-pollinated globe-shaped (GL) $\mathrm{F}_{1}$ seedling tree 87 from the cross $\mathrm{KV} 77119$, a compact (CT) growth habit tree, and a showy-flowered pillar (SFP) tree.

DW gene being either homozygous dominant or heterozygous $\left(C t c t D w_{-} B r b r\right)$. Selfing such a tree would be expected to produce ST, UP, CT, PI, and DW progeny and progeny expressing interactions between these alleles (Fig.1). Field observations placed $\mathrm{F}_{3}$ progeny of $\mathrm{F}_{2} \mathrm{GL}$ trees into six phenotypes: CT, CTPI, GL, PI, UP, and ST (Fig. 4). Pooled chisquare values for $\mathrm{F}_{3}$ progeny of GL parents, KV87962 and KV872526, supported classification of CT vs non-CT trees as was the case for the evaluations of the $\mathrm{F}_{2}$ generation (Table 7). Distinguishing non-CT trees as UP, ST, or PI also resulted in acceptable chi-square values for the segregation of these $\mathrm{F}_{3}$ progeny (Table 7). Classification into the six predicted groups (CT, CTUP, CTPI, ST, UP, and PI) was not supported by chi-square analyses (Table 7) apparently due to the difficulty of distinguishing between the various CT classes resulting from interactions with PI growth form. Although not supported by significant chi-

Fig. 5. Nonpruned $F_{2}$ peach seedlings, 10 years in the field. (A) KV872526, globe-shaped(GL) phenotype ( $3.2 \mathrm{mtall})$, proposed genotype CtctDwDwBrbr and (B) KV872522, compact pillar (CTPI) phenotype $(2.5 \mathrm{~m}$ tall), proposed genotype CtctDwdwbrbr. square values, observations of $\mathrm{F}_{3}$ progeny suggested that the $\mathrm{F}_{2}$ parents KV87962 and KV872526 were CtctDwDwBrbr, the same genotype as had been determined for GL trees evaluated in the $F_{1}$
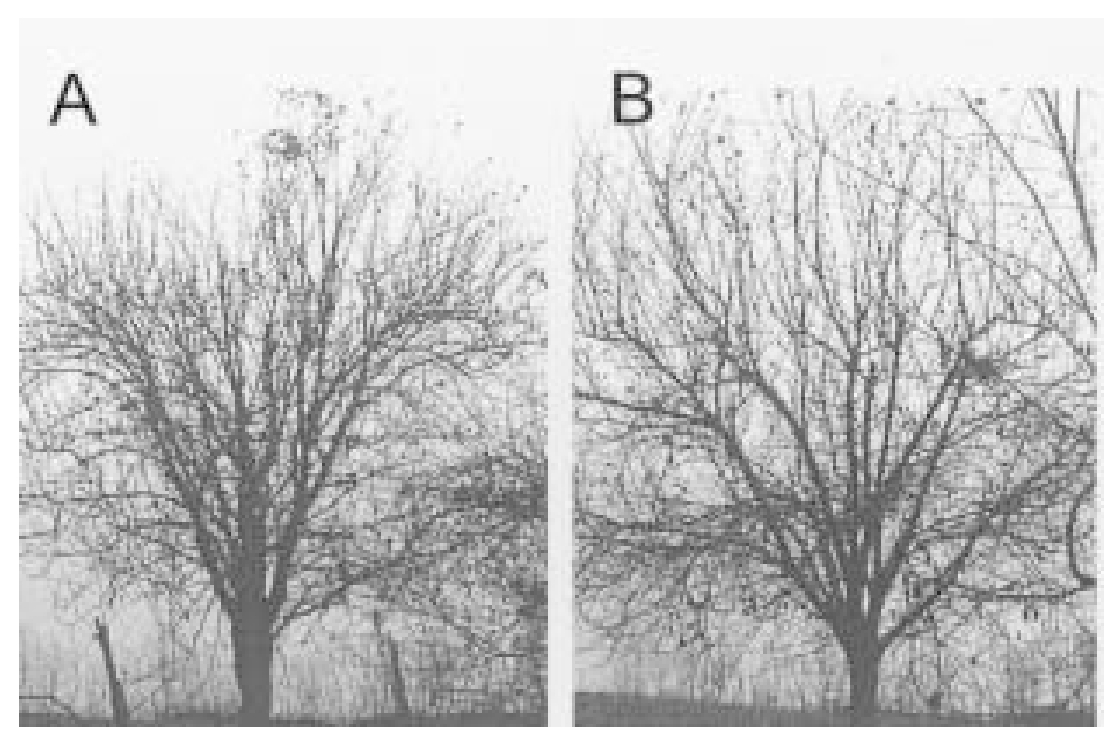


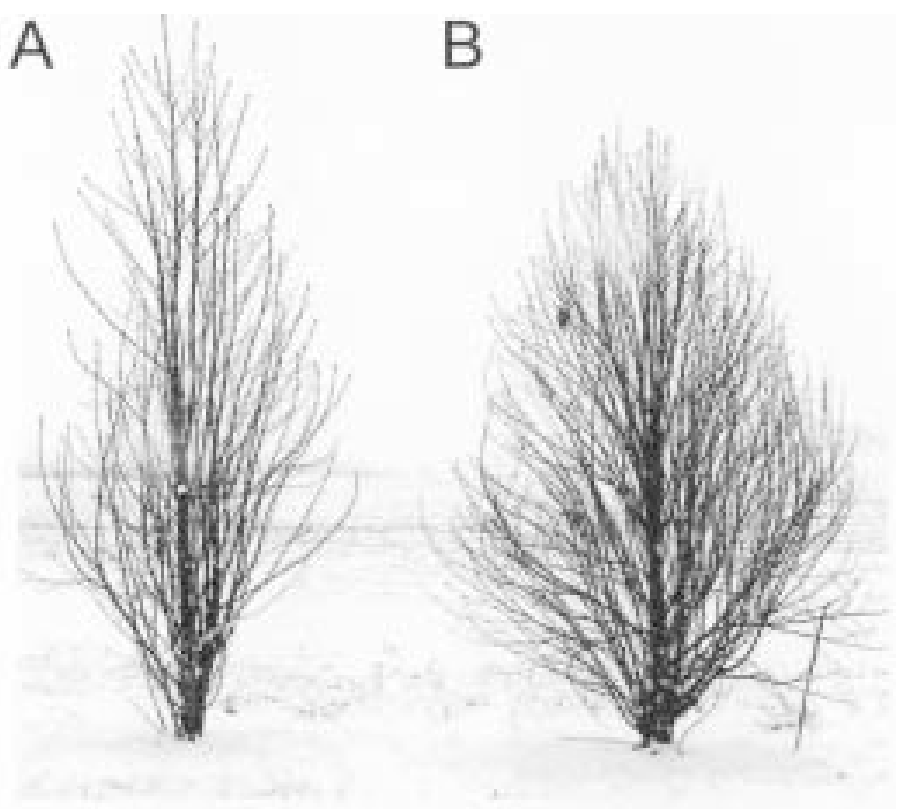

Fig. 6. Nonpruned (A) pillar (PI) (2.6 m tall) and (B) compact pillar (CTPI) (2.2 $\mathrm{m}$ tall) 2 years in the field.

families (Fig. 1). These observations included CT and PI $F_{3}$ trees, trees with apparent interactions of these two growth types, the presence of non-CT trees, and the absence of DW trees.

$\mathrm{F}_{2}$ trees rated as CTPI were difficult to distinguish from those rated as GL, the differences being generally perceptible, but often subtle (Fig. 5). Two CTPI trees were self-pollinated to test if the differences between GL and CTPI trees in the $\mathrm{F}_{2}$ generation, perceived through visual observation, were due to genotypic differences. Progeny of the two $\mathrm{F}_{2}$ CTPI trees displayed segregation markedly different from the GL trees and different from each other. Progeny of the CTPIF $F_{2}$ tree KV872522 were evaluated as PI, CTPI, and DWPI (Fig. 6). Significant chi-square values indicated that KV872522 was CtctDWdwbrbr (Table 8). Another CTPI $\mathrm{F}_{2}$ tree (KV87961), upon self-pollination, produced $96 \mathrm{~F}_{3}$ progeny nearly identical in CTPI growth habit (Fig. 7). The genotype of KV87961 appeared to have been $C t C t D w D w b r b r$. Apparently, the CTPI phenotype is a result of an interaction of the $b r b r$ and $C t_{-}$, whereas the GL phenotype results from an interaction of $\mathrm{Brbr}$ and $\mathrm{Ct}_{-}$. The difference between these two trees in phenotype is that CTPI trees present a form that is more dense and upright than the GL tree which also has a high density of branching, but in a canopy that is subtly less upright. This difference is apparently due to the difference in expression between $\mathrm{Brbr}$ and $\mathrm{brbr}$.

Two $F_{2}$ DW trees were self-pollinated; KV87938, evaluated as an upright dwarf(DWUP) andKV87613, aDWPI(Fig. 8).KV87613 producedallDWPI progeny indicating a $d w d w b r b r$ genotype. KV87938 produced $76 \mathrm{DW}: 14 \mathrm{DWPI}(5.4: 1)$. This parent was expected to beheterozygous for $B r$ andhomozygous for $d w$ in which case an $\mathrm{F}_{3}$ ratio of $1 d w d w B r B r: 2 d w d w B r b r: 1$ $d w d w b r b r$ (phenotypically 1 DW : 2 DWUP:1 DWPI) would have been expected. The deviation from the expected is likely due to difficulties in distinguishing $d w d w B r b r$ (DWUP) from $d w d w B r B r$ (DW). The difficulty in distinguishing $B r b r$ heterozygotes was also encountered in some segregating progenies of standard sized trees as discussed previously.
Table 8. Proposed genotype of compact pillar (CTPI) tree KV87522 ${ }^{\mathrm{z}}$ and genotypic and phenotypic segregation of progeny from self-pollination and phenotype evaluation of progeny of KV87522 and Chi square analysis based on predicted phenotypic ratios.

\begin{tabular}{lcc}
\hline \hline \multicolumn{2}{l}{ Genotype } & Phenotype \\
\hline \multicolumn{2}{l}{ CtctDwdwbrbr (x) } & \\
1 & $C t C t D w D w b r b r$ & CTPI \\
2 & $C t C t D w d w b r b r$ & CTPI \\
1 & $C t C t d w d w b r b r$ & CTDWPI \\
2 & $C t c t D w D w b r b r$ & CTPI \\
4 & $C t c t D w d w b r b r$ & CTPI \\
2 & $C t c t d w d w b r b r$ & CTDWPI \\
1 & $c t c t D w D w b r b r$ & PI \\
2 & $c t c t D w d w b r b r$ & PI \\
1 & $c t c t d w d w b r b r$ & DWPI
\end{tabular}

Predicted phenotypic ratios $=3$ PI: 9 CTPI: 4 DWPI ${ }^{\mathrm{y}}$

Chi square analysis based on the above phenotypic ratios

\begin{tabular}{lccccc} 
KV87522 (x) & PI & CTPI & DWPI & $\chi^{2}$ & P \\
\hline & 13 & 49 & 25 & 1.21 & $0.50-0.70$
\end{tabular}

$\overline{{ }^{\mathrm{Z}} \mathrm{KV} 87522}$ is an $\mathrm{F}_{2}$ progeny of self-pollinated compact pillar (CTPI) $\mathrm{F}_{1}$ seedling tree 87 from the cross KV77119, a compact (CT) growth habit tree, and a showy-flowered pillar (SFP) tree.

${ }^{\mathrm{y}}$ CTDWPI and DWPI could not be visually distinguished, thus all were classified as DWPI

\section{Discussion}

The peach displays a diverse range of genetically-controlled tree forms controlled by expression of multiple loci. Simply inherited tree forms include DW, PI, CT, and WE. The PI habit examined in this study was inherited as a monogenic trait expressing incomplete dominance. Homozygous $\mathrm{BrBr}$ produced ST trees, homozygous $b r b r$ produced PI, and the heterozygote $(\mathrm{Brbr})$ was UP. This finding furthers the work of Yamazaki et al. (1987) and Chaparro et al., (1994) who proposed a simple recessive model of the $B r$ allele. The segregation of trees into $1 \mathrm{ST}(\mathrm{BrBr}): 2 \mathrm{UP}(B r b r): 1 \mathrm{PI}(b r b r)$ was clearly evident in ST x PI crosses. The production of $F_{1}$ UP trees from crosses of DW x PI and WE x PI also support the incomplete dominance model. $\mathrm{F}_{2}$ populations developed from parents containing $b r, d w$, and $C t$ alleles produced trees that could not be classified accurately as ST and UP. Because tree form involves cumulative

Fig. 7. $\mathrm{F}_{3}$ progeny of compact pillar (CTPI) peach KV87961. Proposed genotype of parent and progeny, $C t C t D w D w b r b r$. Tree heights are $\approx 2.7 \mathrm{~m}$.

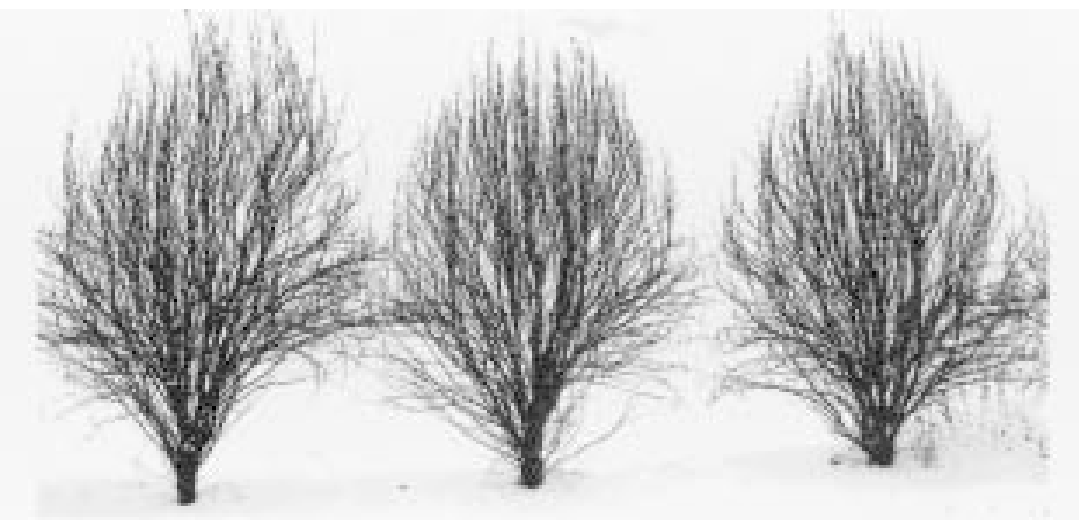



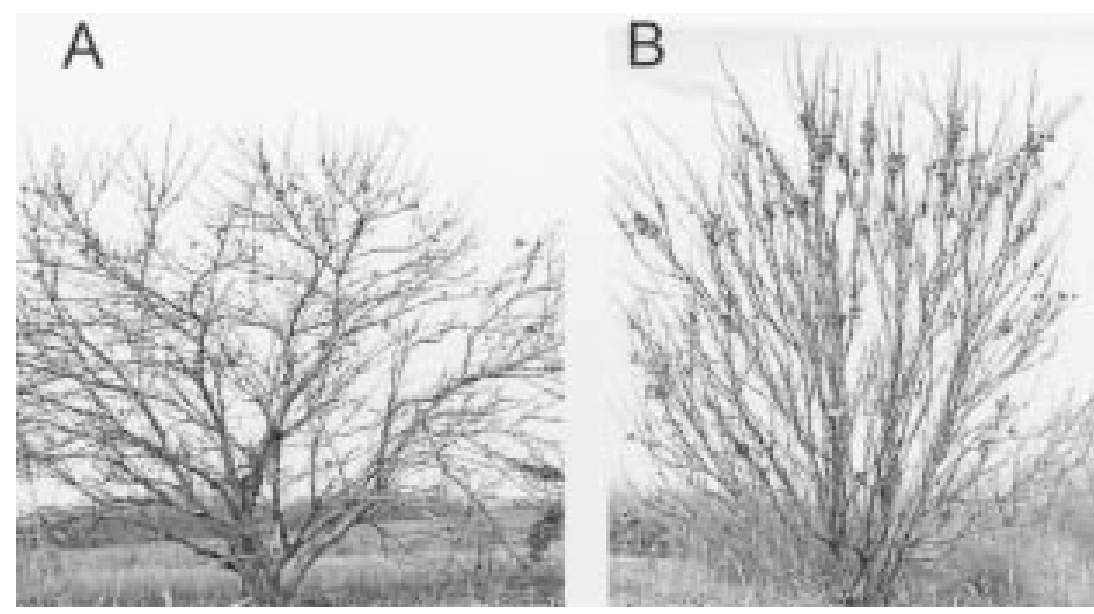

tree growth and productivity by regulated water supply, tree density, and summer pruning. J. Amer. Soc. Hort. Sci. 106:307-312.

Chaparro, J.X., D.J. Werner, D.O'Malley, and R.R. Sederoff. 1994. Targeted mapping and linkage analysis of morphological, isozyme, and RAPD markers in peach. Theor. Appl. Genet. 87:805-815.

Conners, C.H. 1920. Some notes on the inheritance of unit characters in the peach. Proc. Amer. Soc. Hort. Sci. 16:24-36.

Emerson, F.H. and R.A. Hayden. 1975. High density tree walls. HortScience 10:550.

Fideghelli, C., G. Della Strada, R. Quarta, and P. Rosati. 1979. Genetic semidwarf peach selections, p. 11-18. Eucarpia Symp. Tree Fruit Breeding, Angers, 3-7 Sept. 1979.

Glenn, D.M. 2000. Physiological effects of incomplete root-zone wetting on plant growth and their implications

Fig. 8. Nonpruned $\mathrm{F}_{2}$ peach seedlings, 10 years in the field. (A) KV87938 upright dwarf (DWUP) phenotype (2.6 $\mathrm{m}$ tall); proposed genotype $c t c t d w d w B r b r$ and (B) KV87613 pillardwarf (DWPI) (2.4 m tall); proposed genotype $c t c t d w d w b r b r$.

growth and development of the entire tree over several years, it is likely that environmental effects and epistatic (interlocus) interactions contributed to difficulties in tree classification in these particular populations. In the $\mathrm{F}_{3}$ generation segregating for $b r, C t$, and $d w$ alleles, we also noted difficulty in classifying trees with a mixture of traits, especially trees that were thought to be heterozygous for the PI trait combined with DW and/or CT growth habit. Trees expressing combinations of DW and CT, and DW, CT, and PI growth habits could not be distinguished. Future emphasis on DW populations may lead to clarification of these allelic interactions.

In this report we show that distinctly new forms can be produced through a combination of genes. These forms include DWPI (also reported by Yamazaki et al., 1987), CTPI, and GL. Yet there remain other predicted gene combinations (Fig. 1) that we were unable to recognize, perhaps because the differences were too subtle to be readily detected by standard field observation.

Some of the tree forms that have been discussed in this report may have potential for commercial production. The PI and UP forms appear to be particularly suitable to high-density tree wall, fusetto, and central leader-based systems (Bassi et al, 1994; Scorza et al, 2000). Others, such as the DWPI and CTPI, not only present a novel growth form, but these trees maintain a rather small size and compact form. Some bloom profusely and consistently on spurs (Scorza, 1987) requiring little if any pruning in our tests (unpublished). Continued hybridization and development and testing of peach tree growth habits may increase productivity of commercial peach orchards and expand use of the peach as a garden fruit crop and as an ornamental species.

\section{Literature Cited}

Bassi, D., A. Dima, and R. Scorza. 1994. Tree structure and pruning response of six peach growth forms. J. Amer. Soc. Hort. Sci. 119:378382.

Bassi, D. and M. Rizzo. 2000. Peach breeding for growth habit. Acta Hort. 538:411-414.

Brooks, R.M. and H.P. Olmo. 1971. Register of new fruit and nut varieties. List 26. HortScience 6:439-442.

Chalmers, D.J., P.D. Mitchell, and L. van Heek. 1981. Control of peach for irrigation management. HortScience 35:1041-1042.

Glenn, D.M. and S.S. Miller. 1995. Growth, yield, and water use responses of peach to repeated root pruning in a sub-humid climate. HortScience 30:543-546.

Hayden, R.A. and F.H. Emerson. 1979. Pruning high density peach hedge plantings. Compact Fruit Tree 12:76-77.

Hooper, J. 1867. The Italian dwarf peach. Amer. J. Hort. 2:287-288.

Horton, B.D. 1985. Training peaches for completely mechanized production. HortScience 20:244-246.

Lammerts, W.E. 1945. The breeding of ornamental edible peaches for mild climates. I. Inheritance of tree and flower characters. Amer. J. Bot. 32:53-61.

Marini, R.P. and D.S. Sowers. 2000. Peach tree growth, yield, and profitability as influenced by tree form and tree density. HortScience 35:837-842.

Mehlenbacher, S.A. and R. Scorza. 1986. Inheritance of growth habit in progenies of 'Com-Pact Redhaven' peach. HortScience 21:124-126.

Monet, R., Y. Bastard, and B Gibault. 1988. Etude génétique du caractère "port pleureur" chez pêcher. Agronomie 8:127-132.

Scorza, R. 1984. Characterization of four distinct peach tree growth types. J. Amer. Soc. Hort. Sci. 109:455-457.

Scorza, R. 1987. Identification and analysis of spur growth in peach [Prunus persica (L.) Batsch]. J. Hort. Sci. 62:449-455.

Scorza, R., D. Bassi, A. Dima, and M. Rizzo. 2000. Developing new peach tree growth habits for higher density plantings. Compact Fruit Tree 33:19-21.

Scorza, R., G.W. Lightner, L.E. Gilreath, and S.J. Wolf. 1984. Reducedstature peach tree growth types: Pruning and light penetration. Acta

Scorza, R., G.W. Lightner, and A. Liverani. 1989. The pillar peach tree and growth habit analysis of compact x pillar progeny. J. Amer. Soc. Hort. Sci. 114:991-995.

Scorza, R. and W.B. Sherman. 1996. Peaches, p. 325-440. In: J. Janick and J.N. Moore (eds.). Fruit breeding. vol. I. Tree and tropical fruits. Wiley, New York.

Scorza, R., L. Zailong, G.W. Lightner, and L.E. Gilreath. 1986. Dry matter distribution and responses to pruning within a population of standard, semidwarf, compact, and dwarf peach seedlings. J. Amer. Soc. Hort. Sci. 111:541-545.

Strong, W.C. 1867. The Van Buren Golden Dwarf peach. Amer. J. Hort. 2:171-172.

Van Well, R.G. 1974. Com-Pact Redhaven. Fruit Var. J. 28:37.

Werner, D.J. and D.W. Cain. 1985. Cages for protection of tree fruit hybridizations. HortScience 20:450-451.

Yamazaki, K., M. Okabe, and E. Takahashi. 1987. Inheritance of some characteristics and breeding of new hybrids in flowering peaches (in Japanese). Kanagawa Enshi Kempo 34:46-53. Hort. 146:159-164. 